\title{
Application of SCADA Systems in the Coal Mining Industry
}

\author{
Samorodova Lyudmila L ${ }^{\mathrm{a}}$., Lyubimov Oleg V. ${ }^{\mathrm{b}}$, Yakunina Yulia S. . \\ T. F. Gorbachev Kuzbass State Technical University \\ Kemerovo, Russian Federation \\ aluda-sll@yandex.ru; boleg_lyubimov@mail.ru; cyusi_p@mail.ru
}

\begin{abstract}
The possibility of using the Russian complex SCADA-systems in the coal industry due to the urgency of imports substitution in Russian economy has been studied. The structure, properties and advantages of domestic SCADAsystems, which are more competitive in the market of information technologies compared to foreign analogues are described. The relationships between the technical characteristics of domestic SCADA-systems available at the market of production automation in Russia are identified, and the trends of their anticipated development defined. On the basis of statistical data, a comparative analysis of Russian SCADA-systems used in the coal industry of Russia and Ukraine was carried out. A small number of publications on experience of using SCADA-systems explains relevance of the topic. The article gives examples of using domestic SCADAsystems, giving an idea of the positive economic and social impact obtained due to the implementation of the above projects. The authors studies demonstrated the successful use of Russian SCADA-systems in production automation and in addressing existing technical problems in the coal industry.
\end{abstract}

Keywords - enterprise potential, innovations, SCADA system, coal mining, production automation.

\section{INTRODUCTION}

A coal mining operation is a complex dynamic system, affected by numerous random factors of the external and internal environment the changeability of which renders managing processes difficult. The most important means of increasing efficiency of such a system's functioning is developing its innovative potential and implementation of technological and informational innovations. Relevance of the problem increases due to the task to reduce the amount of products imported into our country including those used by Russian manufacturers. This has been stated in the new edition of the Russian Federation State Program "Development of the industry and improve its competitiveness») by 2020. (Resolution no.328 dated April 15, 2014).

\section{MATERIALS AND METHODS}

The target of the present research is the Russian SCADA systems, which enjoyed the most spread during the development of automated processes at the coal mining industry operations.

The aim of the research is to carry out a comparative study of technical characteristics of Russian
SCADA systems, review their practical application in the coal industry, and justify possibilities of their widespread usage in the framework of imports substitution.

In order to achieve the above aims, the following methods were used in this study: correlation analysis of the data, graphic interpretation, methods of grouping and comparative analysis in consideration of the unity of theory and practice.

\section{RESULTS}

The problems of coal industry potential development have been examined in many scientific works. Such Russian and foreign researchers as I. Amosha, B.M. Birenberg, A.I. Kabanov [1], S. Valdajcev [2], Ju.A. Fridman [3], Gurkov I. [4], S.O. Korenkov [5], Holodnjakov D.G. [6], K. Kristensen, M. Rejnor [7] et al. carried out researches in the field of innovative potential of an coal operation. While the issues of manufacturing, economical, HR, and innovative potential have been examined quite thoroughly, the usage of technologies such as SCADA systems enjoyed little attention.

SCADA systems (Supervisory Control And Data Acquisition) are now an integral part of a modern automated processes control system at a production site. SCADA systems were introduced in the end of the $20^{\text {th }}$ century. The introduction of SCADA systems enables a significant reduction of equipment operating costs by reallocating the indication and accumulation of technological information into the AWS dispatcher's console.

Main functions of SCADA systems are software processes monitoring, supervisory control, alarm and event logging, as well as documentation and data archiving.

The current Russian SCADA systems market is represented by foreign and domestic SCADA. The most popular international SCADA systems are: In Touch (Wonderware, USA); iFIX (Intellution, USA); SIMATIC WinCC (Siemens, Germany), Citect (Ci technologies, Australia); RTAP/plus (HP, Canada); Wizcon (PC Soft International, Israel-USA); Sitex and Phocus (Jade SoftWare, UK); Real Flex (BJ Software Systems, USA); Factory Link (US Data Corp., USA); View Star 750 (AEG, Germany); PlantScape (SCAN 3000); Honeywell (USA).

Domestic-made SCADA for PCs were created in Russia in the beginning of the 90 s and they gradually proved their competitiveness by overcoming distrust towards the quality and reliability, continuously improving themselves and 
gaining versatility. At the moment, the Russian market segment is presented by the most well-known and established SCADA systems: TRACE MODE (AdAstra, Moscow); MASTER SCADA («InSAT»); KRUG2000 («KRUG»); CASCADE (AO «Elara»); ZETVIEW (ZAO «Electronic technologies and metrological systems»); Energo SCADA (RPK «Control Systems»); Hardware and software suite «SARGON» (ZAO «NVT-Avtomatika»); Algorythm (ZAO NVP «Bolid»); ASDU «PoliTER» (NPP «Politekh-Avtomatika»); Status-4 (NPP «Avtomatika-C»); «ENTEK» (Engineering centre «ENTELS»); Cascade-SAU (NTO «Tersi-KB»).

Since there is practically no information in academic literature and in the Internet concerning the foreign systems, as well as due to the relevance of the issue of imports substitution in Russia, domestic SCADA systems - the most widespread at coal operations in Russia - were selected for the analysis.

The following factors have called for the necessity of imports substitution: sanction restrictions set by the European Union and the United States on the delivery of Russian high-tech components and software; higher prices for European goods caused by the fall of the ruble; requirements of domestic consumers of the import substitution in the main sectors (nuclear, gas power, metallurgy, coal mining) [8-9].

The Russian systems are import substitutional software products, which fully meet the high requirements for system visualization and control.

Application of domestic SCADA-systems will meet the needs of consumers of the Russian market; reduce risk and cost of the final product without compromising on quality.

It should be noted that the technical support of the Russian software consumer at all stages from design to implementation at the domestic companies is significantly better than that of the western counterparts.

The total absence of language barriers, efficiency of interaction even with remote clients, focus on Russian technical means of automated management control (programmable controllers etc.) also contribute to highquality imports substitution in the field of complex SCADA-systems, which makes the domestic manufacturers more competitive [10-11].

In this regard, the question arises as to how the technical characteristics of the Russian systems meet the requirements of modern automated production.

Comparable technical specs of 12 domestic SCADA systems made publicly available by their developers were used for the analysis. The authors assumed that the developers undertook an independent marketing policy by studying the demand of potential consumers (industries, companies, organizations) in order to specialize their product according to a certain management type, or to impose redundant options through advertisement.

The following technical specs were used as the factors characterizing the SCADA systems:

availability as the main operating system (OC1) Windows, as an additional operating system (OS2) - Linux or QNX;

the number of released versions of software;
- $\quad$ the presence of the development environment;

- the presence of controllers programming environment;

- $\quad$ the presence of the executive system;

- availability of reporting;

- availability of management;

- $\quad$ ability to track alarms;

- $\quad$ type of exchange mechanisms;

- the possibility of scalability;

- $\quad$ the ability to simulate processes;

- the ability to create mnemonics schemes of processes:

- $\quad$ the use of scripts to write the software part;

- $\quad$ the ability to create trends;

- availability of the web-server;

- $\quad$ the use of databases:

- $\quad$ availability of Modbus drivers;

- the possibility of backup.

As for the sampling, the authors have performed cluster analysis, a multivariate statistical procedure that collects the data containing information about the sampling sites, and then organizes the objects into a relatively homogeneous group. Clustering allows you to explore and visualize useful conceptual object grouping diagrams and, based on the data, stimulate hypothetical assumptions. Adoption of the clustering rules (complete linkage method) indicates that the measure of similarity between objects, presumably included into the existing cluster, and any other objects already included in the cluster should not be less than a certain threshold level.

Fig. 1 shows a dendrogram, depicting data of the sampling objects.

The Euclidean distance is used as a measure of the objects dissimilarity:

$$
d_{i j}=\sqrt{\sum_{k=1}^{p}\left(x_{i k}-x_{j k}\right)^{2}},
$$

where $x_{i(j) k}$ is the value of $k$ factor for every $i(j)$ object.

In addition to graphical interpretation of grouping, the examined technical specs of their connection, a correlation matrix was built for the analyzing sampling, studying the significant coefficients of which allows us to draw several hypothetical conclusions:

- relationship of such features as the presence of backup in the system and the number of versions (correlation coefficient 0.68) may indicate that the developers care about the comfort of the user upgrading to a new version without losing information;

- co-existence of the development environment and system alarms tracing (correlation coefficient 0,82 ) enables to easily adjust tracing of the alarms specific to a certain process;

- scalability facilitates proper organization of the executive system (correlation coefficient 0.58);

- simultaneous presence of simulation, scalability and database (correlation coefficients of 0.58 in both cases) suggests that manufacturers are striving to ensure that the simulation under any circumstances was clear, and it was accompanied by the information from the database; 


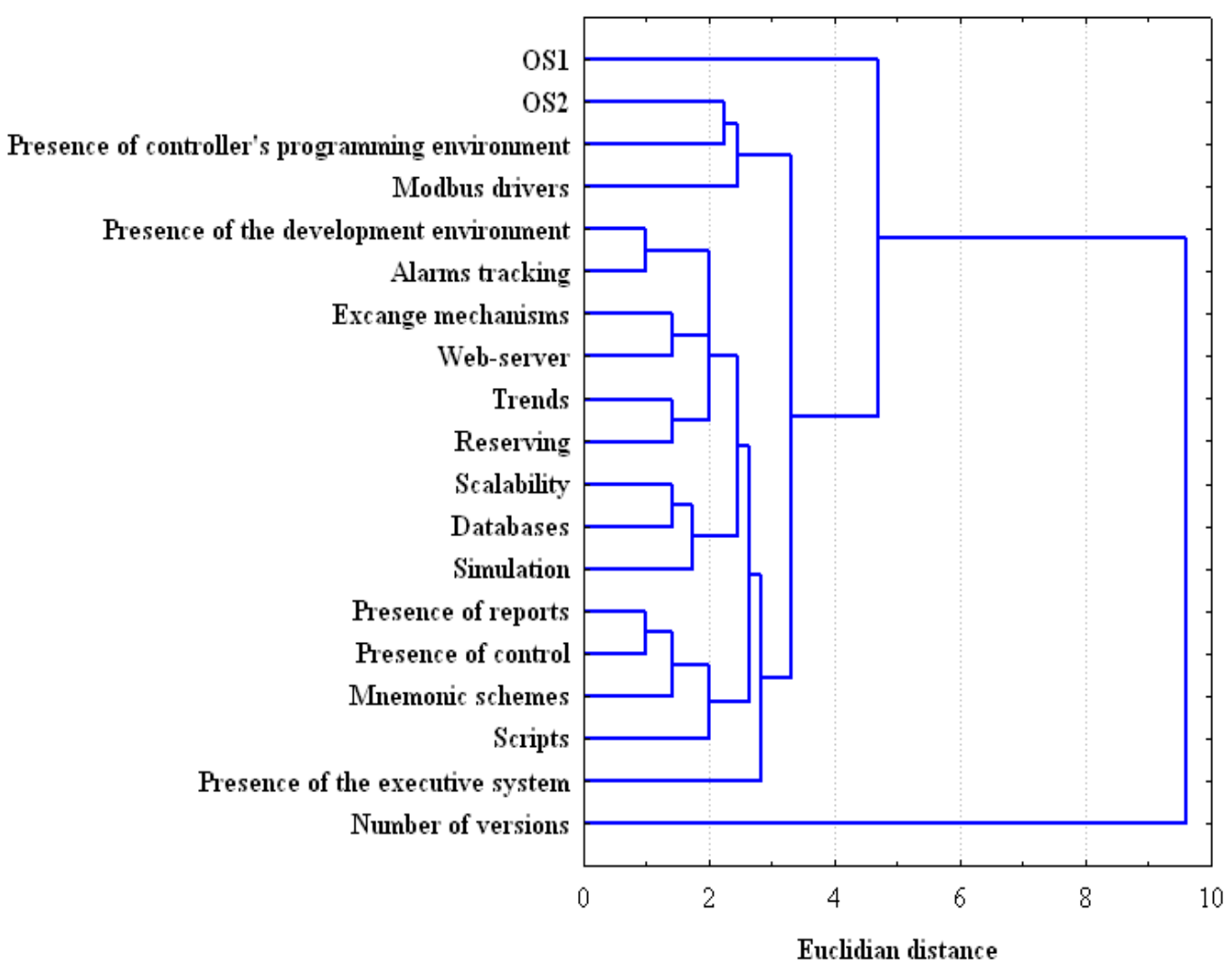

Fig. 1. Dendrogram of full connection method for the sampling examined

- link between the presence of backups and trends (correlation coefficient 0.63 ) explicitly demonstrates the satisfaction of the needs not only in the analysis of the processes taking place, but also in forecasting development trends of these processes;

- presence of exchange mechanisms and the simultaneous presence of the web server (correlation coefficient of 0.63) signifies that developers care about the connection of data from the controller to the task execution level MES (Manufacturing Execution System) via SCADA.

The hypotheses, based on survey data, of course, help to identify trends and patterns in changing SCADA systems' specifications, which will allow consumers to receive objective information and take measures to reduce the risk and the price of the final product without compromising on quality.

Coal mining is becoming a particularly promising sector for the development and implementation of, because it is an important part of fuel and energy complex of the Russian Federation. About seventy-five percent of the coal produced in Russia is used in thermal power plants and in industrial production in the form of fuel, and as a technological raw material in the chemical and metallurgical industries [12].

Long-term operation of coal companies makes mining more complicating, which leads to a decrease in productivity. The most acute problems are transportation of mined coal to the surface and ensuring proper ventilation in coal mining areas. All these parameters significantly reduce the profitability of coal mining enterprises.

All mine construction projects imply development and extraction of deposits from the upper horizon. However, in ten to twelve years any mine clears out the upper horizon and proceed to develop the lower one. That is why larger investment is required to perform complex mine reconstruction works. Such a reconstruction cannot be postponed, as it is in other industries, but must be performed immediately. One of the most promising ways of attracting investment and increasing efficiency of coal mining is using SCADA systems at the mines.

Based on the analysis of data sources, periodicals, the developers' websites and forums discussing the possibility of using SCADA-systems, we have revealed the following most popular systems among Russian customers in the coal industry: Trace Mode, MasterSCADA and CASCADE. The available information allowed carrying out an overview of their implementation in the coal industry. The cost of implementing each project is individual and depends on the current state of the object, needs and financial capabilities of the customer.

Domestic SCADA-system has made a good showing in the cross-border countries (the coal industry of Ukraine).

Comparative analysis of domestic SCADA-systems used in the coal industry of Russia and Ukraine, is presented in Table 1, and allows drawing conclusions on the use of domestic SCADA-system in the following projects. 
TABLE 1. Implementation of domestic SCADA systems in coal industry

\begin{tabular}{|c|c|c|}
\hline$\underset{\text { Z }}{\stackrel{\text { Z }}{\text { Z }}}$ & SCADA systems brief description & $\begin{array}{l}\text { The name of the } \\
\text { project } \\
\text { implemented }\end{array}$ \\
\hline & $\begin{array}{l}\text { It is most common among Russian system } \\
\text { integrators and is used on many objects of } \\
\text { energy, oil, nuclear, chemical, gas, metallurgy, } \\
\text { aerospace industry, utilities and agriculture of the } \\
\text { Russian Federation. It has a convenient technical } \\
\text { support and relatively high cost, which is quite } \\
\text { justified, because in Russia it is the first } \\
\text { integrated SCADA- and softlogic-system that } \\
\text { supports programming through operator stations } \\
\text { and controllers from a single tool, has a unique } \\
\text { technology of autobuilding and magnificent } \\
\text { three-dimensional graphics. } \\
\text { A huge number of installations of «Trace } \\
\text { Mode» at various enterprises is the result of } \\
\text { many years of successful work, intensive } \\
\text { advertising, as well as a flexible pricing policy of } \\
\text { the AdAstra company. }\end{array}$ & $\begin{array}{l}\text { 1. JV "Lenin } \\
\text { mine," } \\
\text { "Artyomugol" } \\
\text { (Gorlovka). } \\
\text { 2. OP "Mine } \\
\text { Russia" } \\
\text { "Selidovgol" SE } \\
\text { (Novogrodovka). } \\
\text { 3. OP "1-3 } \\
\text { Novogrodovskaya" } \\
\text { SE "Selidovugol" } \\
\text { (Novogrodovka). }\end{array}$ \\
\hline & $\begin{array}{l}\text { The «Master SCADA» system is not as well } \\
\text { known on the market as its competitors, but has a } \\
\text { number of attractive features: an easy to learn single } \\
\text { integrated development environment and convenient } \\
\text { technical support. In addition, the system has the } \\
\text { possibility of unlimited expansion of functionality } \\
\text { through the use of third-party products. } \\
\text { Introduced at the consumer market in the past } \\
\text { few years, «Master SCADA», has already } \\
\text { established itself as a SCADA-system is not } \\
\text { inferior to the specs of its competitors and has a } \\
\text { fairly reasonable price. }\end{array}$ & $\begin{array}{l}\text { 1. JSC Kachkanar } \\
\text { GOK "Vanadium" } \\
\text { (JSC "Vanadium") }\end{array}$ \\
\hline 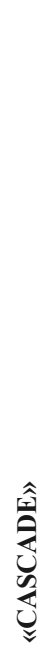 & $\begin{array}{l}\text { SCADA-system "CASCADE" is used for the } \\
\text { construction of automated process control systems } \\
\text { (PCS), automated control and accounting of energy } \\
\text { systems (AMR), the automated systems of } \\
\text { operational dispatch management (ADCS) and other } \\
\text { industrial automation systems. "CASCADE" has } \\
\text { successful experience in applications in the } \\
\text { chemical, petrochemical, gas, metallurgy, electric } \\
\text { power industries and utilities. Its main advantages on } \\
\text { the market of domestic systems are the following } \\
\text { features: the use of free database - SQL-server } \\
\text { InterBase 6/Firebird, high speed data archiving; } \\
\text { convenient means of viewing the operational and } \\
\text { historical information: detailed mimic, trends, } \\
\text { dynamics; compatibility with any domestic and } \\
\text { foreign controllers with OPC server (with an } \\
\text { interface to the OPC server access module); } \\
\text { possibility of independent development of access } \\
\text { modules to specific devices' data, extensions and } \\
\text { any additional visualization module objects. }\end{array}$ & $\begin{array}{l}\text { 1. Automation of } \\
\text { Processing Plant } \\
\text { JSC "Amur Coal". } \\
\text { 2. ACS "Vesovoy } \\
\text { Potok" at JSC } \\
\text { "Cascade". } \\
\text { 3. Automation of } \\
\text { crushed stone } \\
\text { quarry (Obninsk). }\end{array}$ \\
\hline \multicolumn{3}{|c|}{$\begin{array}{l}\text { We know about the successful development of APCS } \\
\text { esovoy Potok" on the basis of SCADA "CASCADE", } \\
\text { olied at the coal-mining enterprise "Amur Coal" } \\
\text { lagoveshchensk). The following facilities were installed } \\
\text { the processing plant of the company: plate recognition } \\
\text { tem and weighing video surveillance system, which } \\
\text { ludes four video cameras in housings, a set of connecting } \\
\text { oles, and transmission of the video signal to the APC. The } \\
\text { tem of automatic traffic control along the scales is } \\
\text { ovided by four industrial LED traffic lights, traffic lights } \\
\text { atroller, a set of connecting cables and specialized } \\
\text { tware. }\end{array}$} \\
\hline
\end{tabular}

The automating product ASPC "Vesovoy Potok" was installed at the facility, and data exchange with $1 \mathrm{C}$ by XML files was set.

Alongside with the implementation of this SCADA system, a similar ASPC was developed at the colliery undertaking JSC "Cascade" (Krasnosulinsky District in Rostov Oblast). The main aim was to automate the technological process of weighing the vehicles and it was carried out through the following functional capabilities: determining the moment of weighing and weighing process systems' initiation; photographing and recognition of the vehicle's number, as well as recording the video of the weighing from the arrival at the scales to the exit from them; printing receipts/documents (scale tickets) for the driver immediately after the weighing of the product; a full set of tools for the integration of the weighing system with BAAN ERP-system, SAP/R3.

Thus, at the static vehicle scales all vehicles passing through the check point are automatically recorded, their weight is automatically saved not only in the local database APCS "Vesovoy Potok", but also transferred directly into the accounting system (SAP/R3, 1C etc.). Also, a fully autonomous weighing is performed, excluding the weight of the operator from the process, leaving him only the functions of control, monitoring and software control of the process via APCS "Vesovoy Potok" in case of an emergency, almost completely eliminating the human factor from the weighing process, i.e.: weight, the vehicle number and entrance time are recorded automatically, the automatics control the movement of the vehicle through the scales, as well as prevents/allows all phased TC weighing cycle on its own.

"CASCADE" was also successfully used during the implementation of an automated "KPP" control system at EvroAktiv Estate enterprise (Obninsk). The object of automation implementation was truck scales.

The main features of APCS "KPP":

1. Pass creation.

2. TC passage control through a checkpoint with photofixation.

3. Work with barriers: control is possible in automatic or manual mode.

3.1. With automatic fixation of numbers and a pass on a vehicle, the barrier will open, after its passing - it will automatically close.

3.2. When manually entering the numbers and omissions on a vehicle, the barrier works the same as in the automatic mode.

4. Event logging of passes and unauthorized events.

4.1. Pass events are created if there is a pass on a vehicle.

4.2. Unauthorized events are created when a vehicle does not have a pass.

Applying the APCS allowed to increase the weighing facility capacity, reduce the cost of personnel and eliminate its impact on the weighing process [13].

The constructed system of APCS MasterScada at OJSC Kachkanar mining and processing combine "Vanadium" (JSC "Vanadium") allows you to automatically control the quality of the ore crushing in crusher plant, allowing to 
optimize the process of crushing and achieve reduction of production and operating costs [14].

The "Petrovsky Coal Machinery Plant" (Donetsk, Ukraine), authorized system integrator of the AdAstra company used SCADA TRACE MODE 6 for the development and implementation of safety system UTAS (unified telecommunications system of supervisory monitoring and automated mining machines and technological complexes control). The UTAS system is designed to provide comprehensive safety, continuous monitoring of parameters of mine workings air, mining equipment and technological systems, machine and technological systems control, transferring information to the control room, processing and display, improving human resource management efficiency.

The UTAS mining safety system performs the following functions:

- collecting data on the state of the environment and mining equipment in the mine workings;

- primary processing of the information received;

- issuing control commands to the electrical and mining equipment;

- data transmission into the SCADA system controller on the surface;

- performing analysis of the collected information according to a predetermined algorithm;

- making decision and issuing control commands or recommendations to the dispatcher.

Control sensors and UTAS mining safety system devices are made by the "Petrovsky Coal Machinery Plant". SCADA system TRACE MODE 6 by AdAstra Research Group, LTD (Moscow, Russia) is used at the dispatcher level. This software meets all technical requirements and UTAS mining safety system working conditions.

The terms of reference submitted to the developers of the system was met, including largely thanks to competent selection of SCADA TRACE MODE 6 software, which has proved to be at its best in such parameters as:

- reliability;

- performance;

- selectivity;

- an optimal price/performance ratio;

- versatility (supporting the whole range of equipment);

- availability and simplicity of learning;

- intuitive user interface;

- visualization at remote workstations;

- technical assistance in Ukraine and the Russian Federation.

After successful introduction of mining safety systems UTAS, in the near future it is planned to introduce this system at 26 more Ukrainian mines. It can be stated that the SCADA TRACE MODE 6 will continue to provide reliable and trouble-free operation of the whole complex at most enterprises of Ukrainian coal industry.

\section{CONCLUSIONS}

Thus, based on the cluster analysis of the technical characteristics of the SCADA-systems and systematization of practical experience in the coal industry, we have revealed that the systems most in demand by consumers in the coal industry are: Trace Mode, MasterSCADA and CASCADE. These systems have clear competitive advantages, such as a userfriendly interface, versatility (supporting the whole range of equipment), the availability and simplicity, an optimal price/performance ratio. Of great importance is the fact that the support of Russian customers at all stages from design to implementation in domestic firms is much better than that of the Western counterparts.

\section{REFERENCES}

[1] Amosha, A.I. Methods of managing innovative processes in Ukranian coal industry - A.I. Amosha, B.M. Birenberg, A.I. Kabanov. - NAS Ukraine. - IEP. - Donetsk, 1999. - 39 p.

[2] Valdaytsev, S.V. Technological innovations management. Edited S.V. Valdaytsev and N.N. Molchanova. - Saint-Petersburg.: SPbSU, 2004. $-150 \mathrm{c}$.

[3] Fridman, Yu.A. Coal business as the foundation of innovative development of Kuzbass - A. Fridman, G.N. Rechko, Ye.Yu. Loginova. Vestnik KuzSTU. - 2013. - \#6. - p. 139-143.

[4] Gurkov I.B. Competitiveness and innovativeness of Russian manufacturing enterprises. - I.B. Gurkov, Ye.M. Avraamova, V.S. Tubalov. Economics Issues. - 2005. - \#2. - p. 40-52.

[5] Korenkov, O.V. Controlling enterprises development potential. Monograph. Kiev.: GROT, 2004. - 289 p.

[6] Kholodnyakov D.G.. Justification of volumes of mining and capital works in the construction of coal mines - D.G. Kholodnyakov, S.O. Miller, L.K. Samorodova. Vestnik KuzSTU. - \#2. - 2015. - p. 60-61.

[7] Christensen C., Raynor M., 2004. The innovator's solution creating and sustaining successful growth. Harvard Business School Publishing.

[8] Dezhina I., Ponomarev A., Frolov A., 2015. Advanced Manufacturing Technologies in Russia: Outlines of a New Policy. Foresight and STI governance. Journal of the National research university Higher School of Economics. \#1.

[9] Apokin A., Belousov D., Salnikov V., Frolov I., 2015. Long-term Socioeconomic Challenges for Russia and Demand for New Technology. Foresight and STI governance. Journal of the National research university Higher School of Economics. Vol.9, \# 4.

[10] Analysis of competitive advantages of domestic SCADA systems on the market of production automation in Russia / I.V. Bogachev, L.L. Samorodova, Yu.S. Yakunina O.V. Lyubimov // Role technical sciences in social development: The International Scientific and Practical Conference proceedings (Novemver 26-27, 2015). Kemerovo: Vestnuk KuzSTU, 2015. - p. 14-19.

[11] Korneev, V.A.. Development of registering-diagnosing devices monitoring systems with Web-technologies - V.A. Korneev, A.S. Dobrynin, A.S. Ivanoc, R.S. Koynov. KuzSTU. - 2015. - \#6. - p. 157-162

[12] On the question of using modern SCADA systems in Russia - I.V. Bogachev, L.L. Samorodova, Yu.S. Yakunina O.V. Lyubimov. Automation systems in education, science and industry: Proceedings of $\mathrm{X}$ All-Russian scientific and practical conference (17-19 December 2015). Sib. State Industr. University: edited S.M. Kulakova, L.P. Myshlyaeva. - Novokuznetsk : SibSIU, 2015. - p. 176-178.

[13] Implementation of «Cascade» [Electronic resource] - Access mode: http://it-rostov.ru/avtomatization/vnedrennie-resheniya/\#. - Screen title.

[14] Official Site of Master Scada [Electronic resource] - Access mode: http://www.masterscada.ru/?additional_section_id=84. - Screen title.

[15] SCADA TRACE MODE 6 in coal mines safety systems - UTAS [Electronic resource] http://www.adastra.ru/news/coalua/. - Screen title. 